\title{
Bridging mining theory with soil remediation
}

\author{
T. Karachaliou \& D. Kaliampakos \\ Laboratory of Mining and Environmental Technology, \\ School of Mining Engineering and Metallurgy, \\ National Technical University of Greece, Greece
}

\begin{abstract}
Soil contamination has been a major problem all over the world posing great risks to human health and the environment. Currently there are many remedial alternatives that can be applied, yet the available funds are not enough to entirely face the problem. The optimal use of the available resources by maximising their environmental benefits is of great interest. With this aim in mind, a method based on mining theory is proposed in this paper. The core idea is contamination to be treated as a "negative" ore. The meaning of "negative" is attributed to the fact that contamination, contrary to the ore, is an unwanted asset. In this case, what is actually waste is considered valuable. However, the rationale is the same since in both cases the profit is proportional to the grade of the extracted ore or the concentration of the removed contaminant. This approach enables the use of pit optimisation tools such as the Floating Cone method suitably developed to be implemented in soil remediation. The main problem to overcome seems to be the absence of an economic value attributed to the removal of contamination. The paper also introduces a method to define a shadow price in order to compare the profit of contaminated soil removal to the corresponding total cost of this action. As a case study, the method is applied in a contaminated site in Lavrion, Greece.

Keywords: soil remediation, environmental risk, block modelling, pit optimisation.
\end{abstract}

\section{Introduction}

During recent decades the modern world has been increasingly concerned about contaminated land. The problem of soil contamination seems to be expanding since new brownfield sites are discovered at every turn, whereas the available funds remain inadequate to rehabilitate them all. According to some estimates, 
there are about 1,500,000 possibly contaminated sites in the European Union and their remediation cost may exceed 100 billion euro [1]. The need for methodologies aiming at the optimisation of the available funds is strongly emerging.

The methodology described in this paper is based on techniques of the mine design theory, and the pit optimisation in specific, and is suitably developed so as to be used in the remediation planning. The concept is to treat contamination as a "negative" ore and evaluate alternative remediation schemes on a cost-benefit basis. The soil remediation project that was undertaken at a former metallurgical site in Lavrion, Athens is used to demonstrate the applicability and utility of the methodology.

\section{Pit optimisation theory}

The purpose of any pit optimisation methodology is to estimate the actual ore reserves (tonnage and grade) by combining economics, geometries and ore distribution. The process involves the superposition of a geometric surface called a pit onto the mineral inventory. The size and shape of the pit depends upon economic factors and design/production constraints. With an increase in price the pit would expand in size assuming all other factors remained constant. Within the pit are found materials of differing value. Economic criteria are applied to assign destinations for the materials based on their value (i.e. mill, waste dump, etc.), see fig. 1 .

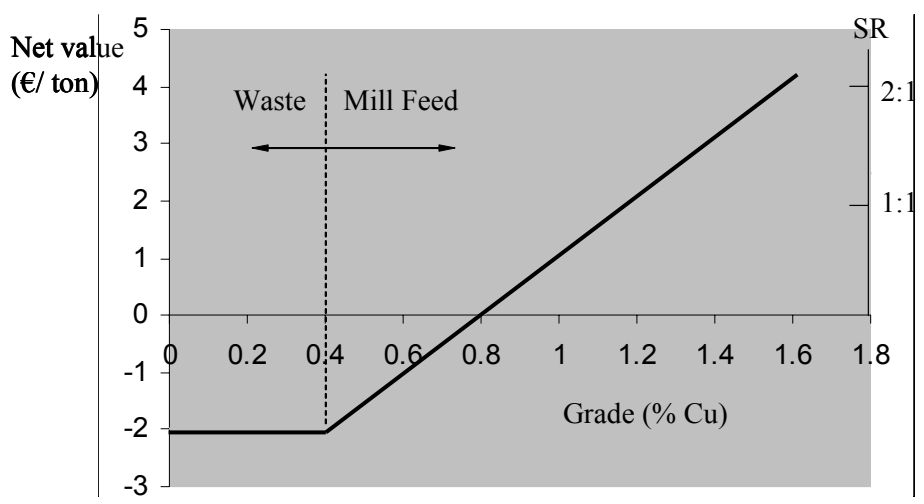

Figure 1: Net value-grade curve showing the waste/mill split.

In order to uncover the ore, waste has to be removed. Ore is distinguished operationally from waste by the cut off grade. The cut off grade is the grade at which the mineral resource can no longer be processed at a profit [2]. Ore above cut off can be treated and sold at a price equal to or above 'break even'. Material below this cut off is waste [3]. The choice of the cut off grade in mining influences the profitability and life of individual mines and thereby the quantity of a resource that is available to society. The optimal cut off grade depends on all the salient technological features of mining, such as the capacity of extraction 
and of milling, the geometry and geology of the orebody, and the optimal grade of concentrate to send to the smelter [4].

The amount of waste that must be removed to release a given ore quantity is described by the "stripping ratio". The ratio is most commonly expressed as in eqn (1).

$$
\mathrm{SR}=\text { Waste (volume)/ Ore (volume) }
$$

The break even stripping ratio describes the situation when the costs involved in mining the strip just equal the revenues. The break even cut off grade is defined as that grade for which the net value (gross value minus total cost) is zero [2].

An important input into the economic viability of a mine is the determination of the ultimate pit limit of the ore body. That is, that contour which is the result of extracting the volume of material that provides the total maximum profit whilst satisfying the operational requirements of safe wall slopes. The ultimate pit limit gives the shape of the mine at the end of its life [5]. The standard procedure of pit optimisation is as follows.

An important task in mine management is the establishment of an accurate model for the deposit. The block model is extensively used in optimisation. The regular 3D fixed-block model is the most commonly used and is best suited to the application of computerised optimisation techniques. This model is based on the ore body being divided into fixed-size blocks. The block dimensions are dependent on the physical characteristics of the mine, such as pit slopes, the dip of the deposit and grade variability as well as the equipment used. The centre of each block is assigned, based on drill hole data and a numerical technique (such as inverse distance weighting or krigging), a grade representation of the whole block. Using the financial and metallurgical data the net profit of each block is determined. To satisfy the mine site safety and stability requirements, wall slope restrictions are imposed on each block. From these we can identify for each block $\mathrm{x}$ the set $\mathrm{S}_{\mathrm{X}}$ of blocks that must be removed before block $\mathrm{x}$ can be mined. This collection of blocks is usually referred to as "cone".

The ultimate open pit limit problem is that of determining the contour that satisfies the safe wall slope and which yields the maximum profit. Mathematically, this problem can be formulated as follows. Consider an ore body with $\mathrm{N}$ blocks. Let $\mathrm{p}_{\mathrm{i}}$ be the net value (profit) of block $\mathrm{I}$ and $\mathrm{S}_{\mathrm{i}}$ the set of overlying blocks associated with block I [6]. The ultimate pit problem can be written as in equation 2 .

subject to

$$
\text { Maximise } \quad \sum_{i=1}^{N} p_{i} \times x_{i}
$$

$$
\begin{aligned}
& \mathrm{x}_{\mathrm{i}}-\mathrm{X}_{\mathrm{j}} \leq 0 \text { for all } \mathrm{i} \text { and } \mathrm{j} \text { and } \mathrm{j} \in \mathrm{S}_{\mathrm{i}} \\
& \text { and } \mathrm{x}_{\mathrm{i}}=0,1 \text { for all } \mathrm{i}
\end{aligned}
$$

The limits define the amount of ore minable, the metal content, and the associated amount of waste to be moved during the life of the operation. The material contained in the pit will meet two objectives. A block will not be mined unless it can pay all costs for its mining, processing, and marketing and for stripping the waste above the block. For conservation of resources, any block 
meeting the first objective will be included in the pit. The result of these objectives is the design that will maximize the total profit of the pit based on the physical and economic parameters used.

The stripping ratio is used to set the pit limits on each section. The pit limits are placed on each section independently using the proper pit slope angle. The pit limits are placed on the section at a point where the grade of ore can pay for mining the waste above it. When a line for the pit limit has been drawn on the section, the grade of the ore along the line is calculated and the lengths of the ore and waste are measured. The ratio of the waste and ore is calculated and compared to the breakeven stripping ratio for the grade of ore along the pit limit. If the calculated stripping ratio is less than the allowable stripping ratio, the pit limit is expanded. If the calculated stripping ratio is greater, the pit limit is contracted. This process continues on the section until the pit limit is set at a point where the calculated and breakeven stripping ratios are equal [7].

The ultimate pit limit problem is easy to formulate mathematically, but not so easy to solve because of its size. One of the methods that are widely applied in pit optimization is the "floating cone". It works by searching through the block model for ore blocks and then assessing the value of the inverted cones that have to be mined to expose them. If the value of a cone is positive, it is mined out and all the blocks it includes are changed to air blocks. The search then continues. The process is repeated for each ore block in a deposit, considering cone overlaps. The term "floating" is derived from the "movement" of the cone throughout the model. The optimal pit could be defined as the one yielding maximum profit, maximum net present value or maximum extraction.

\section{Contamination as a "negative" ore: the basic concept}

Pit optimisation techniques can be adjusted to optimise the allocation of the funds in soil remediation. In this case, what is actually waste (contaminated soil) is considered as the valuable ore, and the profit of extraction derives from the elimination of environmental risk. The process is quite similar. Contamination is first of all explored by drilling probe holes in the area of interest. The contaminated area is then divided into blocks. Each block is assigned a contamination value (such as contaminants' concentration) using interpolation methods. The economic value of each block is then calculated. The extraction of a contaminated block is obviously profitable, in terms of human health and environmental protection. However there is no actual "price" (e.g. euro per ton of removed contaminated soil) that can be used to estimate the economic value of each contaminated block. In order to determine a shadow price a basic assumption is made that the profit of excavating a block is zero when the contamination value is equal to the applied standard. The net value of the removal of contaminated soil above the applied thresholds is considered positive. The net value of the removal of soil below the applied thresholds is considered negative. This limit is corresponding to the break even cut off grade, the contamination level for which the net value (gross value minus total cost) is zero. 


\section{Application in Lavrion}

The site under consideration is located in Lavrion, Athens, within an area of 24.5 hectares. It has a long industrial past, which resulted in a severe environmental problem $[8,9]$. Contamination was detected through out the site, to an average depth of 5 meters. Given the high volumes of contaminated soil and the limited budget that was available, a special application of the "dry tomb" technique was implemented ex situ but on site [10]. Contaminated soil was excavated, transferred and disposed off in a secure, water-tight construction within the boundaries of the site. In total $113.000 \mathrm{~m}^{3}$ of contaminated soil were excavated and transferred in the repository. The total cost of the project was approximately 3.5 million euro corresponding to about 31 euro per ton or 16 euro per $\mathrm{m}^{3}$ of contaminated soil. With regard to these economic data, the optimal excavation limits and depths will be defined.

The contamination value that needs to be investigated is the leaching of arsenic. The described technique is applied in a subarea of the site to define the optimal excavation contour that maximises the environmental risk reduction given the available budget. Eighty samples through sixteen drill holes to a final depth of five meters were used for the analysis. Table 1 lists the arsenic leaching values based on the procedures described in 2003/33/EC Council Decision [11]. The area was divided into blocks $25 \mathrm{~m}$ long $\mathrm{x} 25 \mathrm{~m}$ wide $\times 1 \mathrm{~m}$ high. Figure 2 shows a plan and a section view of the block grid and the location of the drill holes.

Each block is assigned a leaching value using the inverse distance weighing method. The shadow price is then calculated based on the rationale described

Table 1: $\quad$ Arsenic leaching values ( $\mathrm{mg} / \mathrm{kg}$ dry substance).

\begin{tabular}{cccccc}
\hline \multirow{2}{*}{ Drill hole } & \multicolumn{5}{c}{ Depth } \\
\cline { 2 - 6 } & $\mathbf{0 ~ m}$ & $\mathbf{1 ~ m}$ & $\mathbf{2 ~ m}$ & $\mathbf{3} \mathbf{~ m}$ & $\mathbf{5 m}$ \\
\hline Dh5 & 0.05 & 0.20 & 0.07 & 0.13 & 0.42 \\
Dh6 & 0.07 & 0.10 & 0.06 & 0.08 & 0.13 \\
Dh7 & 0.54 & 0.22 & 0.24 & 0.6 & 0.05 \\
Dh8 & 0.1 & 0.11 & 0.05 & 0.05 & 0.05 \\
Dh9 & 0.16 & 0.06 & 0.05 & 0.05 & 0.05 \\
Dh10 & 0.05 & 0.09 & 0.05 & 0.17 & 0.05 \\
Dh11 & 0.13 & 0.58 & 0.13 & 7.3 & 252 \\
Dh12 & 0.39 & 0.07 & 0.05 & 0.05 & 0.05 \\
Dh13 & 0.05 & 0.05 & 0.05 & 0.11 & 0.36 \\
Dh14 & 0.13 & 0.07 & 0.07 & 0.1 & 0.05 \\
Dh15 & 0.41 & 0.05 & 0.05 & 0.05 & 0.05 \\
Dh16 & 0.11 & 18.50 & 0.05 & 0.66 & 0.05 \\
Dh17 & 0.05 & 0.09 & 0.38 & 1.21 & 0.08 \\
Dh18 & 223.8 & 46.40 & 56.3 & 0.28 & 0.05 \\
Dh19 & 0.18 & 0.28 & 0.08 & 0.07 & 0.05 \\
Dh20 & 0.05 & 0.05 & 0.07 & 0.05 & 0.05 \\
\hline
\end{tabular}



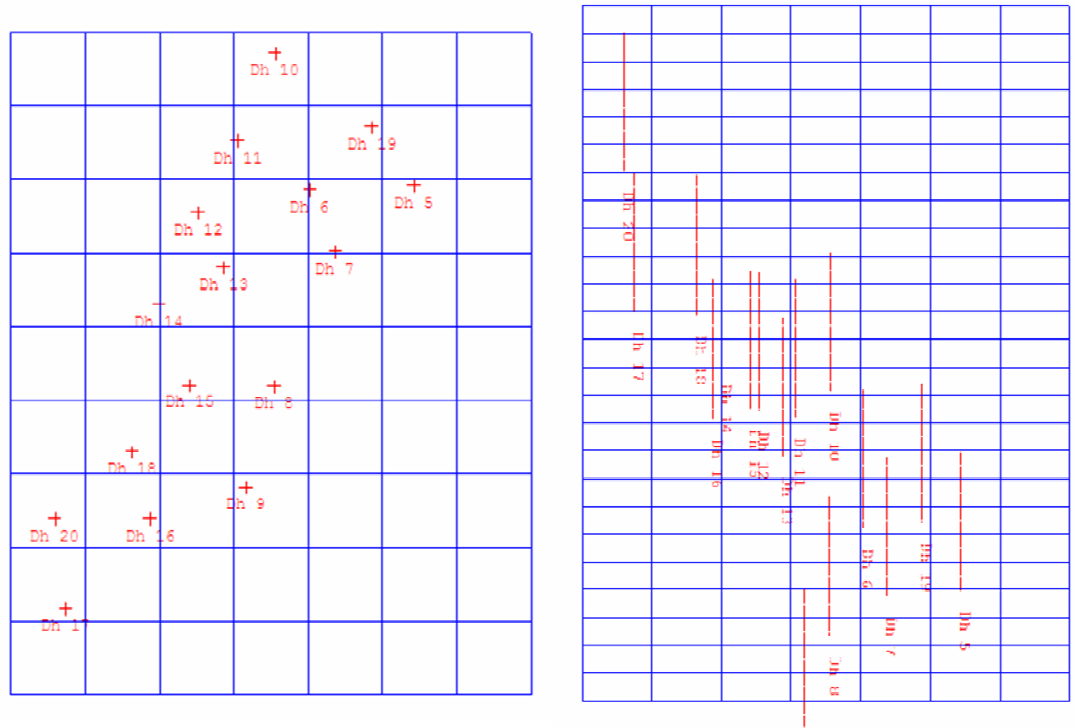

Figure 2: $\quad$ Plan and section view of the block grid and the drill holes.

above. The leaching limit value for non hazardous waste is $2 \mathrm{mg} / \mathrm{kg}$ dry substance, $2 * 10^{-3} \mathrm{mg} / \mathrm{ton}$. The net value (gross value-cost) of excavated blocks with this value is zero (eqn.(3)). This is expressed as follows:

$$
\begin{gathered}
V-C=O \\
L \times S P=C \\
S P=\frac{C}{L} \\
S P=\frac{16 \text { euro } / \text { ton }_{\text {soil }}}{2 m g_{\text {As }} / 10^{3} \text { ton }_{\text {soil }}} \\
S P=8 \times 10^{-3} \text { euro } / \mathrm{mg}_{\text {As }}
\end{gathered}
$$

where $V$ denotes the gross value (euro/ ton ${ }_{\text {soil }}$ ), $L$ the leaching limit value $\left(\mathrm{mg}_{\text {substance }} /\right.$ ton $\left._{\text {soil }}\right), \mathrm{C}$ the cost (euro/ ton $\left.{ }_{\text {soil }}\right)$ and SP the shadow price (euro/ ton $\left._{\text {soil }}\right)$

The shadow price per ton of the contaminated soil is estimated to be $8^{*} 10^{-}$ ${ }^{3}$ euro/ $\mathrm{mg}_{\mathrm{As}}$. Thus the net economic value $P$ (euro/ton) is calculated from the leaching value, $l\left(\mathrm{mg}_{\mathrm{As}} / \mathrm{ton}_{\text {soil }}=10^{3} \mathrm{mg}_{\mathrm{As}} / \mathrm{kg}_{\text {soil }}\right)$ as in eqn (4).

$$
\begin{gathered}
P=l \times S P-C \\
P\left(\text { euro } / \text { ton }_{\text {soil }}\right)=l\left(\mathrm{mg}_{A s} / \text { ton }_{\text {soil }}\right) \times 8 \times 10^{-3} \text { euro } / \mathrm{mg}_{A s}-16 \text { euro } / \text { ton }_{\text {soil }}
\end{gathered}
$$

Therefore blocks that have a leaching value less than 2 are assigned a negative economic value, whereas blocks that have a leaching value more than 2 are assigned a positive economic value. 
A computerised floating cone method, by means of CSMINE software, is implemented. CSMINE is a mine planning and design software accompanying the book by Hustrulid and Kuchta [2]. The purpose is to define the optimal excavation contour, in other words the blocks that need to be excavated in order to optimise the use of the available funds and maximise the environmental profit. The maximum depth of excavation is quite low (5 meters), so it was decided to consider the sides almost vertical. A slope angle of approximately $75^{\circ}$ was selected that is proved not to cause any stability problems. Table 2 provides information on all the blocks that shape the optimal excavation outline.

Table 2: Leaching value and net profit of the blocks that should be excavated.

\begin{tabular}{cccccc}
\hline $\begin{array}{c}\text { Block } \\
\text { number }\end{array}$ & $\begin{array}{c}\text { Leaching } \\
\text { value } \\
(\mathbf{m g} / \mathbf{k g})\end{array}$ & $\begin{array}{c}\text { Net } \\
\text { profit } \\
(\boldsymbol{€})\end{array}$ & 17 & 0.12 & $-4,688$ \\
\hline 1 & 0.05 & $-4,875$ & 18 & 0.22 & $-4,440$ \\
2 & 0.05 & $-4,875$ & 19 & 0.17 & $-4,567$ \\
3 & 144.64 & 356,603 & 20 & 3.85 & 4,615 \\
4 & 129.75 & 319,373 & 21 & 2.41 & 1,033 \\
5 & 101.75 & 249,366 & 22 & 3.6 & 3,988 \\
6 & 48.97 & 117,430 & 23 & 6.32 & 10,791 \\
7 & 18.55 & 41,376 & 24 & 23.42 & 53,540 \\
8 & 6.83 & 12,082 & 25 & 104.7 & 256,760 \\
9 & 10.31 & 20,769 & 26 & 3.19 & 2,965 \\
10 & 25.12 & 57,806 & 27 & 5.06 & 7,649 \\
11 & 33.51 & 78,786 & 28 & 9.08 & 17,703 \\
12 & 12.45 & 26,119 & 29 & 15.71 & 34,280 \\
13 & 4.11 & 5,285 & 30 & 34.17 & 80,432 \\
14 & 4.42 & 6,038 & 31 & 159.74 & 394,355 \\
15 & 4.24 & 5,606 & 32 & 15 & 32,498 \\
16 & 0.31 & $-4,213$ & 33 & 14.21 & 30,532 \\
\hline
\end{tabular}

Figures 3 and 4 show two sections (East-West and North-South) of the final pit limit. The discontinuous line shows the surface elevation and the thick line marks the ultimate pit outline. The economic net value of each block is also shown. The blocks that need to be removed are shown in grey.

The figures show that not all positive valued blocks can be excavated. For instance, block $(504050,4175035,20)$ in Figure 4 valued at +2.709 shouldn't be removed because the cost to excavate the overlying blocks is more than the net profit from that action. Figure 5 shows in plan view the number of blocks that should be removed in the downward direction. The discontinuous lines indicate the orientation and location of the mentioned sections.

According to the floating cone technique 33 blocks (10,313 tons) should be removed, 27 of them have positive economic value (leaching value more than 2 ) 
100 Brownfields IV

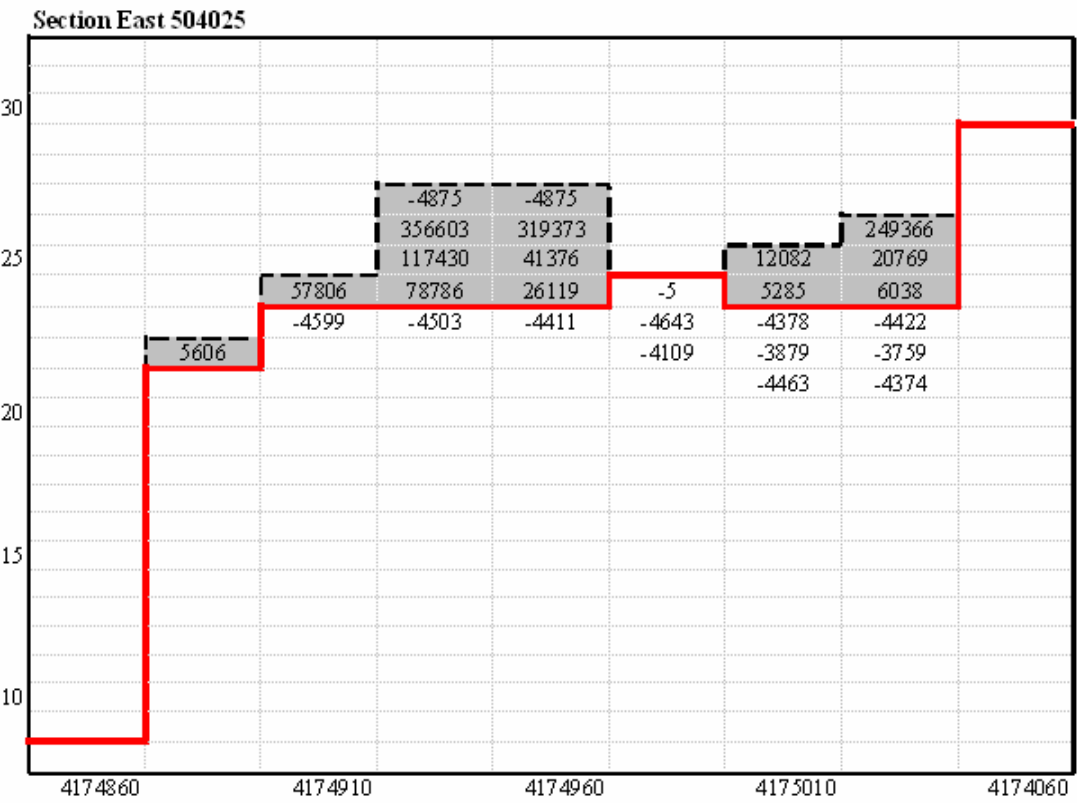

Figure 3: Section North-South at Easting 504025.

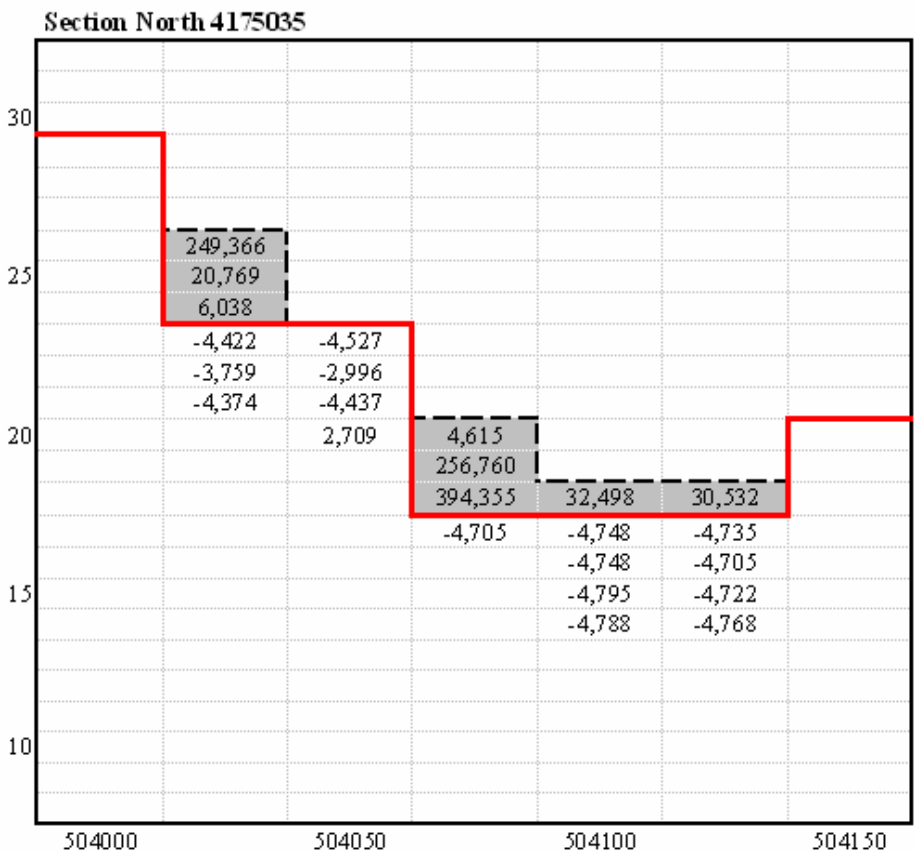

Figure 4: $\quad$ Section East-West at Northing 4175035. 


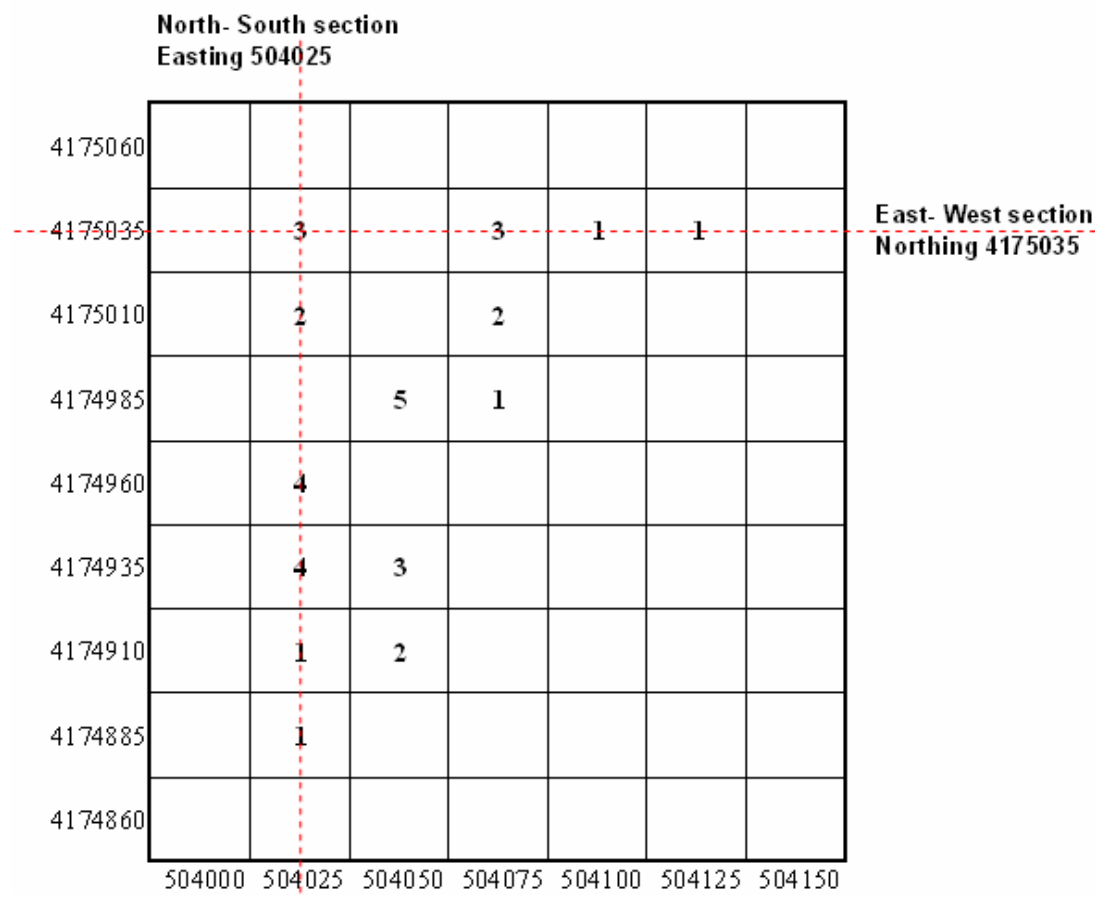

Figure 5: $\quad$ Plan view showing the number of blocks that should be removed in a downward direction.

and 6 have negative value. The average leaching value of these blocks is 28.7 $\mathrm{mg} / \mathrm{kg}$ dry substance. The net profit of this pit is estimated to be 2,169,588 euro. This number, obviously, doesn't have an absolute meaning. It depends on the basic assumptions that were made.

\section{Conclusions}

By transferring mining theory into soil remediation, an approach aiming at the optimisation of the available remediation funds is developed and presented in the paper. Contamination is treated as a negative ore. Although it has a negative meaning, the removal of contaminated soil, as with ore extraction, has a positive value. It is considered profitable, in terms of environmental protection. In fact the environmental benefit is proportional to the level of the contamination (e.g. the concentration of the contaminants).

Corresponding to the pit optimisation theory, the Floating Cone method can be used to determine the optimal excavation outline. The absence of an economic value attributable to contaminated soil is overcome by a basic assumption. The contaminants' concentration limit value is the break even limit at which the net profit is considered zero. This way, a shadow price is produced to be assigned to contaminated soil and the net profit of the excavated soil can be estimated. The 
methodology can be of great value especially in cases where the available budget is not enough to clean up all the volume of contaminated soil, which is usually the case. The results most probably do not indicate the excavation of the whole range of contaminated soil. The optimal excavation contour, the exact location and depth, is identified in order to guide the optimal use of the remediation funds.

\section{References}

[1] European Environment Agency, Environment in the European Union at the turn of the century. Soil degradation, Ch. 3.6, (1999), pp. 192.

[2] Hustrulid, W. \& Kuchta, M., Open pit mine planning and design. Volume 1-Fundamentals, Balkema Publishers, Brookfield.

[3] Lane, K. F., The economic definition of ore cut-off grades in theory and practice, Mining Journal Books Ltd, London, 1988, 149pp

[4] Cairns, R.D. \& Shinkuma, T., The choice of the cutoff grade in mining, Resources Policy 29 (2003) 75-81

[5] Caccetta, L., Application of optimisation techniques in open pit mining

[6] Caccetta, L.\& Kelsey, P.J., Models for Mine Site Rehabilitation, Proc. MODSIM 2001 International Congress on Modelling and Simulation

[7] Laurich, R., Planning and Design of Surface Mines, Society for Mining, Metallurgy, and Exploration, Inc. (SME).

[8] Karachaliou, T. \& Kaliampakos, D., Redeveloping derelict urban space, the case study of Lavrio, Greece. CABERNET 2005 - The International Conference on Managing Urban Land, Belfast, Northern Ireland, UK, 2005.

[9] Karachaliou, T., Damigos, D., \& Kaliampakos, D., Risk assessment in heavily contaminated lands. CEST 2007 - 10th International Conference on Environmental Science and Technology, September 5th-7th, 2007, Greece.

[10] Kaliampakos, D., Damigos, D. \& Karachaliou, T., Using the "dry tomb" technique in the remediation of heavily contaminated land, (SWEMP 2007), December 11-13, 2007, Bangkok.

[11] 2003/33/EC: Council Decision of 19 December 2002 establishing criteria and procedures for the acceptance of waste at landfills pursuant to Article 16 of and Annex II to Directive 1999/31/EC. 